\title{
Tracking the Division of Labour through Handprints: Applying Reflectance Transformation Imaging (RTI) to clay 'tokens' in Neolithic \\ West Asia
}

\author{
AUTHOR NAMES AND AFFILIATIONS \\ Dr. Lucy E. Bennison-Chapman *a \& Dr. Lori D. Hager ${ }^{\mathrm{b}}$ \\ a Archaeology Department, Bülent Ecevit University, Zonguldak, Turkey. Email: \\ bennisonchapman@aol.com \\ b Pacific Legacy Inc., Berkeley, California, USA. Email: $\underline{\text { dhager@gmail.com }}$ \\ (*Corresponding author)
}

\begin{abstract}
The residents of Boncuklu Höyük, a mixed forager-farming community dating to the pre-ceramic Neolithic c. mid- $9^{\text {th }}$ to mid- $8^{\text {th }}$ millennium cal. BC, used their hands to manipulate local clays into artefacts, often leaving behind traces of their palm prints and fingerprints on the surface of the objects. Reflectance Transformation Imaging (RTI), a digital imaging technique that uses multiple images and mathematical models to reveal the 3-dimensional shape of an artefact's surface, provides a detailed, post-processing interactive view of the prints on each artefact. Geometric clay objects are the singlemost abundant artefact category at Boncuklu Höyük with over 1,000 clay objects recovered and studied at this central Anatolian village to date. The aim of the project is to understand the manufacture, use, and disposal of geometric clay objects at Boncuklu Höyük through an analysis of the hand and fingerprints present on their surfaces. RTI reveals palm and fingerprints on more than half of the study sample consisting of eighty-eighty clay artefacts. Analysis of the prints using friction ridge density protocols indicates that adult females were the primary makers of the artefacts. The results were unchanged when taking into account artefact shape and type, and when considering temporal and locational data. The association of these artefacts during manufacture principally to women suggests an early link in the life of the object to women, potentially suggesting a gender based division of tasks at Boncuklu Höyük.
\end{abstract}

\section{KEYWORDS}

Boncuklu Höyük, Neolithic, clay object, fingerprints, Reflectance Transformation Imaging (RTI), West Asia, Anatolia, "token". 


\section{HIGHLIGHTS}

Reflectance Transformation Imaging detects hand and fingerprints on clay artefacts. Neolithic "tokens" were intentionally crafted artefacts.

Friction ridge density analysis identifies age and sex of clay artefact producers.

Adult females were the main producers of clay objects ("tokens") at Boncuklu Höyük.

The study suggests a gender-based division of labour in Neolithic village communities.

\section{Introduction}

Palm prints and fingerprints found on clay artefacts from archaeological contexts contribute to an understanding of the division of labour in the past when an appropriate methodology is used to enhance their detection. This study utilises a sophisticated technique relatively new to archaeology, Reflectance Transformation Imaging (RTI). By highlighting human fingerprints and palm prints on clay artefacts, friction ridge density analysis can be undertaken, allowing the relative age and sex of the manufacturer to be assessed. To demonstrate the potential of this technique, an enigmatic artefact type: small, geometric clay objects, or "tokens" are studied. The case-study site of Neolithic Boncuklu Höyük, central Anatolia, provides an impressive sample size; eighty-eight clay artefacts were photographed and analysed. The case study also has important implications for our understanding of the function of early clay objects, and Neolithic societies in general.

Small, geometric clay objects (henceforth clay objects) first appear in the archaeological record of South-West Asia in the $10^{\text {th }}$ millennium cal. BC, at for example Çayönü (Broman Morales 1990: 667274-75, pl. 25-26), PPNA Jericho (Kenyon \& Holland 1983: 814, fig. 367 p. 356), PPNA Gesher (Garfinkel \& Dag 2006: p. 157, fig. 6.1: 3-4) and Sheikh-e Abad (Matthews et al.2013: 140, 141, table 11.5 p. 142). Clay objects continue to be found at a larger number of sites across the region throughout the PPNA, into the PPNB (i.e. Es-Sifiya, Aswad, Nevalı Çori, Mureybet and Munhata: de Contenson 1995; Mahasneh \& Gebel 1998; Morsch 2002: 145-47, 149, fig. 2; Ibáñez 2008: tbl. 1 p. 662; Y. Garfinkel pers. comm.). By the ceramic Neolithic, clay objects are a common feature on some sites, yet remain absent from others (Bennison-Chapman 2014: chapters $9 \& 10$, appendices A \& E). The appearance of clay objects in the archaeological record of the Neolithic period in the Near East coincides with the onset and development of fundamental economic, social, and technological innovations including most importantly, the emergence of the world's first sedentary agricultural villages. Until very recently, research into the distribution, form and function of clay objects has focused almost 
exclusively on the proto-literate period onwards, with the earliest, Neolithic examples lacking publication and detailed analysis (Bonora et al. 2014; Forouzan et al. 2012; Nashli \& Moghimi 2013). From the mid to late $4^{\text {th }}$ millennium $\mathrm{BC}$, it is clear that clay objects were part of a complex administration system. They were used in south Mesopotamia and Elam alongside seals, sealings, hollow spherical clay envelopes or "bullae" and early administrative texts (Leo Oppenheim 1959; Nissen et al. 1993: pp. 11-13, fig. 113 p. 130 and chronological chart fig. 3 p. 5; Robinson 2007: 60-61, 62-62; Sampson 1985: 57-61; Schmandt-Besserat 1992: 7, 108-110, 129-130; Schmandt-Besserat 1996: $7,102)$. Recently completed research examining thousands of Neolithic examples has shown that there is no correlation between "token" distribution according to region, time period, site size, or on-site activities within the Neolithic of West Asia (Bennison-Chapman 2013, 2014). The range of shapes, degree of standardization and assemblage composition varies greatly from site to site. Variability is also evidenced in the nature of sites yielding "tokens", and the immediate contexts in which they are found (e.g. refuse contexts, domestic contexts, administrative contexts, possible ritual contexts). All evidence supports the interpretation of clay objects as utilitarian, potentially fulfilling a variety of uses within and across settlements.

\subsection{Who were the makers?}

Despite recent research, many unanswered questions remain as to the manufacture and use of clay objects, and the nature of Neolithic society more generally. Using the case-study site of Boncuklu Höyük, the overall aims of the project are twofold. Firstly, to better understand clay objects as an artefact category we ask: Who made and used these objects? How did the Boncuklu Höyük people use the small objects, and how did the objects function more broadly within the settlement and its households? Were they made alongside other small clay artefacts and did diminutive objects have similar functions? Previous studies on Neolithic clay objects are scant, and have inferred that these plentiful, crudely made objects are accidently made, or perhaps they represent items for play made by small children (i.e., Broman Morales 1983). The ubiquity of handprints on the clay objects suggests more direct association of the maker to the object than can be accounted for by accident. For clay objects with prints of adequate size for analysis, clear detection of the prints is provided by the RTI imaging technique. Based on the metric analysis of the prints, identification of the maker(s) can be made within a broad age range (child versus adult) and by biological sex if the maker was an adult. Comparison of the demographic information of the makers of clay objects to that of the makers of figurines, beads and pottery gives additional evidence to the potential location and context of use, along with the value imbued on the clay object. Sanders (2015) studied fingerprints on pottery at Tell Leilan, an Early and Middle Bronze Age site in Syria dated to 3200 to 1500 B.C.E. Based on an analysis of the prints, Sanders found a change over time in the sex of the pottery makers, from females to males. She linked this shift to an increase in urbanization and the formation of the state. The Neolithic period was one of considerable change in all spheres of life, including social organisation. In this context, gender roles, 
relations and identities are likely to have experienced fundamental change at the onset and during the course of the Neolithic (Bolger 2010). This research has the potential to compliment the growing research interest in this field.

This project is one of the first projects of its kind in the Neolithic South-West Asia. As such, it was uncertain if RTI would be successful in detecting, capturing and enhancing fingerprints well enough to enable an analysis relative to the age and sex of the makers. The presence of finger and palm impressions on Boncuklu Höyük's clay objects was evident on just over $6 \%$ of all studied samples (as evident by studying the object surface using a hand lens). Yet it was suspected that RTI would reveal fingerprints on a larger proportion of clay objects and other artefacts made of clay where palm and fingerprints are not immediately evident to the naked eye. Other evidence of hand use on clay objects such as finger impressions can also be studied using RTI. In a study undertaken in 2013 by one author (LDH), nonprint data was revealed in detail on two clay pottery objects from Yeşilova Höyük, a Neolithic site near Izmir, Turkey, primarily in the form of fingertip indentations and impressions of the finger shafts (Hager unpublished). Similar questions regarding the makers of the pottery relative to age and sex were considered in the Yeşilova research endeavour. The results of the Yeşilova print analysis suggest adult females and a child made the marks on the clay objects.

\subsection{Neolithic Boncuklu Höyük}

Boncuklu Höyük is located on the Konya Plain in central Turkey, approximately $9.5 \mathrm{~km}$ north east of the larger, well-known, Neolithic site of Çatalhöyük. Boncuklu Höyük is a typical Neolithic mound, covering over one hectare in area (Fig. 1) (Baird et al. 2012). Occupation at this small, mixed subsistence community dates to $\mathrm{c}, 8,300-7,500 \mathrm{cal}$. $\mathrm{BC}$; the earliest phases are contemporary to nearby $9^{\text {th }}$ millennium BC Pınarbaşı, the later levels predate the earliest settlement at nearby Çatalhöyük East by a few hundred years (Baird et al. 2012: 221). Many explanations have been proposed for the when, how, and why of the development of sedentism, cultivation, and herding in Central Anatolia, and the Konya Plain is key to understanding this phenomena (Colledge et al. 2004; Fuller et al. 2011; Fuller et al. 2012). Boncuklu Höyük's temporal setting between the earlier Pınarbaşı and the later Çatalhöyük East can give evidence of site interactions relative to the movement of people, ideas and technologies across the landscape (Baird et al. 2018; Baird 2012: 183, 192; Baird et al. 2012: 221, 233; Watkins 1996). Results to date illustrate a central Anatolia where farming was adopted by indigenous foragers rather than being introduced by farmers from outside the region (Baird et al. 2018; Baird Forthcoming; Baird et al. 2012: 219).

\subsection{Boncuklu Höyük's Geometrics and other clay artefacts}

Vast quantities of small, geometric shaped clay objects (commonly known as "tokens") (Fig. 2) have been retrieved by thorough sieving and/or flotation of $100 \%$ of excavated sediment at Boncuklu Höyük. 
The abundance of the clay objects contrasts with the comparatively scant number of figurine fragments, vessel fragments and clay beads. By the end of the 2017 excavation, more than 1,000 geometric clay objects had been registered, constituting more than half of all recorded small finds at the site (Baird pers. comm.). There are few other clay artefact types at the site although the comparatively scant clay figurine fragments, ceramic vessel fragments and clay beads are very distinct (Fig. 3) (Baysal 2013; Fletcher et al. 2017).

The presence of more highly crafted items highlights the very basic nature of the production of clay object assemblage. Their simple nature, crafted from an abundant, easily obtainable raw material may have allowed the objects to hold multiple changing symbolic meanings and practical functions, fluid and $a d-h o c$ in nature. It seems plausible that the objects at Boncuklu may have been used as simple counting aids, yet a single, overarching function may not fit the diversity of these artefacts. In fact, multiple roles, including their use in gaming, divination and the casting or drawing of lots, as well as for simple counting.

\section{Materials: Artefact selection}

The RTI digital imaging capturing sequence and preliminary processing was carried out during the 2013-2015 field seasons. Small, geometric clay objects were the project's primary artefact focus. To date, 1,156 clay objects from Boncuklu Höyük have been individually studied, their shape and dimensions recorded, and their manufacture, use-wear and find contexts examined. Initially using a hand lens to inspect the clay surface, the presence or absence of palm prints, fingerprints and shallow fingertip depressions (nail impressions) was recorded. Other noted variables included clay texture and surface finish. Three quarters of the clay objects fall into three basic 3-Dimensional shape categories: sphere, ovoid and disc. The average object weight is $3.38 \mathrm{~g}$ and the average dimensions fall between 1$2 \mathrm{~cm}$ (as recorded in all three dimensions). Clay objects are common in all phases of occupation, excavation areas and in many context types, yet middens (open air refuse dumps, activity-spaces and platforms) are the most common context ( $47.58 \%$ of clay objects). In addition to clay objects, a smaller number of other clay artefacts were included in the study for comparison, including figurine fragments, a small sample of clay beads/pendants, pottery fragments and miscellaneous (unidentified) clay artefacts. In total, 88 clay artefacts were imaged, with 101 RTI images created (seven artefacts were imaged on two surfaces, obverse/reverse; two artefacts were imaged on three surfaces). The total study artefact count includes 65 clay objects, 11 figurines (all fragments), seven Neolithic pottery sherds, two clay beads/pendants and three miscellaneous clay artefacts (Fig. 4, Table 1).

\section{Methodology: Detecting and analysing palm prints and fingerprints from Boncuklu hands}

During the Neolithic, the hands were vital to the manufacture of the clay objects. The Boncuklu Höyük 
people worked the wet clays with their hands, shaping and forming the objects, often resulting in the transfer of palm prints and fingerprints onto the surfaces. The soft substrate typical of wet clays provides an excellent medium for hand impressions. The ridges characteristic of human palm prints and fingerprints, known as "friction ridges" or "epidermal ridges", can be left intentionally or inadvertently. Palm prints and fingerprints are found on all human hands; they are a product of genetics and the in utero environment, and therefore they are entirely unique to each individual. Handprints in clay, known as "plastic" prints, are moulds in reverse of the actual prints, and give direct evidence of the maker's hand. Palm prints and fingerprints represent the hand of a specific and unique individual, the person(s) directly associated with the object when it was moist, likely its maker, and thus the prints tell a story of that object and the person shaping it.

\subsection{Reflectance Transformation Imaging (RTI)}

When prints or print-like marks are suspected, a digital imaging technique called Reflectance Transformation Imaging (RTI) provides sufficient detection and illumination of the object's surface for a detailed analysis. Based on the predictable pattern of light reflection off the surface of objects, RTI images are taken in a specific format using a stationary camera, a prime lens, and an external flash unit (Cultural Heritage Imaging 2013a; Malzbender 2001; Mudge et al. 2012). Reflective spheres placed in each frame record the exact light positions of the flash at each position and angle (Fig. 5). RGB colour information is also collected during this process. The highlight RTI technique (H-RTI) was chosen over the use of the dome highlight technique (D-RTI) due to the ease of transporting and using a stationary camera in the field, the limitations of lab space on-site, and the overall cost of the dome setup.

Using the RTI Builder software (v.2.0.2) (Cultural Heritage Imaging 2013b, 2013c), the RTI composite image is built from the multiple images of each surface based on the mathematical descriptions of the light vectors ("surface normals") reflecting off the surface of the object per pixel in the image set and on the colour data. The files are viewed through an interactive RTI viewer that allows for relighting of the surface from any direction in multiple rendering modes. The topography of the artefact's surface is highlighted in great detail as the light moves across it. RTI has been successfully used on a variety of artefacts and structures from archaeological sites and objects housed in museums, using 2-Dimensional images to derive the 3-Dimensional shape of the surfaces for analytical and archival purposes (Mudge et al. 2006; Redman \& Mudge 2007; Mudge et al. 2010; Schoerer 2012; Schneider \& Hager 2017).

\subsection{Palm Print and Fingerprint Analysis}

An in-depth analysis of the surfaces of eighty-eight clay artefacts (clay objects, figurines, pottery and beads) from Boncuklu Höyük was undertaken to identify the individual or individuals associated with 
the clay artefacts during manufacture. Using the processed images from the RTI capturing sequence, the epidermal ridges on the clay objects were observed through the interactive RTI viewer. The examination first considered whether human hands made the marks, and if so, whether the palm prints and/or fingerprints could reveal the maker's identity relative to age and sex.

The differences between the hands of adults and children hand are substantial and well documented. In general, the overall size of the hand discerns children from adults, and for palm prints and fingerprints, friction ridge density is a key factor (Ashbaugh 1999; Kamp et al. 1999; Králík \& Novotný 2005; Sanders 2015; Taduran et al. 2016). Defined as the number of friction ridges per $25 \mathrm{~mm}^{2}$, children typically have a high ridge density $\left(15-16\right.$ or more ridges $\left./ 25 \mathrm{~mm}^{2}\right)$ relative to adults $(14-15$ ridges or less per $\left.25 \mathrm{~mm}^{2}\right)$.

The hands of modern human males and females are sexually dimorphic in the breadth of the hand, the density of the friction ridges, and the relative finger lengths for digits F2 and F4 (Ashbaugh 1999; Gutierrez-Redomero et al. 2008; Nayak et al. 2010; Acree 1999; Kamp et al. 1999; Králík \& Novotný 2005, Sanders 2015; Taduran et al. 2016). Male hands tend to be wider than female hands, and are characterized by low ridge densities and broad ridge patterns. By contrast, females tend have small hands and have prints with high ridge densities and narrow ridge patterns.

Epidermal ridges were highlighted, identified and described based on the RTI images. Since the images rendered from the RTI process represent a composite using multiple original capture images, the metric analysis of the prints was done on a single original capture image. The original capture images were taken in planar view with a metric scale in the frame. The RTI image confirmed the presence and extent of the ridges in the original captures images to ensure accurate measurements. Print areas were measured for ridge densities per $25 \mathrm{~mm}^{2}$. When the print area was large enough, multiple print areas were measured for ridge density at each $25 \mathrm{~mm}^{2}$. If the ridge count differed in the multiple areas, ridge density was averaged. Because age and sexing criteria of hands and prints rely mainly on differences due to body size, the age range is broad (adult or child) and sex determination of the adults takes into consideration an overlap zone.

\subsection{Study of diagnostic prints, their makers, and the context of their deposition}

The contextual distribution of the artefacts according to age and sex were analysed and mapped against pre-existing object contextual data. The diagnostic artefacts were studied in detail, looking for any trends related to the demographic result (male/female and adult/child), the type of artefact (i.e., figurine, pottery or clay object, and nature of clay object) and its context within Neolithic settlement of Boncuklu Höyük. For the non-diagnostic artefacts, those where demographic information could not be obtained, basic information (artefact type, context code, season excavated) alongside the results of the RTI study 
(such as "inconclusive due to too few or faint prints" or "no finger/palm prints") and any further comments noted against the RTI image were summarised.

\section{Results}

Of the 88 clay artefacts studied (including 65 clay objects and 23 clay artefacts of various other typological classifications: Fig. 4 \& Table 1), fingerprints or palm prints were detected on 57 of them, with clear and diagnostic prints found on 50 (56.82\%) of imaged artefacts (Table 1). The RTI technique worked equally well on most artefact types; 38 clay objects ( $58.46 \%$ of studied clay objects) revealed a diagnostic finger or palm print, mirroring the high overall success rate (Table 2).

All small, geometric clay objects had been individually studied, and the presence or absence of human finger or palm prints noted. The RTI technique provided excellent detection of the epidermal ridges compared to those noted by eye and/or with the hand lens. The quality of the fingerprints from the RTI images were primarily clear and well demarcated although some prints were faint and shallow. Only seven of the 50 print containing artefacts had impressions too faint or too small to be analysed, and a further five of the imaged artefacts revealed fingernail impressions or finger-tip depressions clear from prints (Table 3). Our understanding of the distribution of fingerprints and palm prints, which are more common than had been observed previously, was increased using RTI.

Of the 50 diagnostic artefacts, the overwhelming majority, seventy-eight per cent $(n=39)$, displayed a finger/palm print belonging to an adult female (Fig. 6). Twenty per cent $(\mathrm{n}=10)$ of diagnostic artefacts had the print of an adult male (Fig. 7), and a single child (representing 2\%) was identified (Fig. 8). Seventy-six per cent of diagnostic objects are small, geometric clay objects, of which seventy-eight per cent reveal female prints (39 out of 50, Table 4); therefore the demographic patterning is strong for clay objects alone (Fig. 9). The demographics on the prints seen on figurines follow the overall patterning, with six of the seven diagnostic figurine prints belonging to adult females (Table 4, Fig. 9). Yet in contrast, diagnostic pottery fragments have equal proportions of adult male and adult female prints. Two prints from diagnostic artefacts had friction ridge densities within the overlap zone of sexual differentiation and were indeterminate for sex (Table 5).

No patterning is observed regarding demography, appearance and/or manufacture when considering only the clay objects ( $\mathrm{n}=38$ diagnostic artefacts). Clay objects of all size ranges, shapes, types, and finishes were equally likely to have been predominantly manufactured by an adult female. The proportion of male to female prints found on objects of each main 3-dimensional shape, for example, remains consistent (Fig. 10). The studied artefacts overwhelming come from three excavation areas, M, $\mathrm{H}$ and $\mathrm{P}$ and equal $76 \%$ of all photographed artefacts. When considering only the diagnostic artefacts, 
the same proportions are true, demonstrating that the distribution of diagnostic fingerprints is equal across all excavation areas (Fig. 11). Clay objects, as the most numerous artefact category, dominate the diagnostic artefact type within all areas of the site, excepting Area P, which has a concentration of "other" clay artefact types, constituting a small majority within this area (Fig. 11). When comparing the distribution of clay artefacts across Boncuklu Höyük, along with their demographic result, the distribution is random. The study sample does not support the notion that in different areas of the site, people of a specific age or sex were producing clay artefacts (Fig. 12). The counts reflect the density of sediment excavated in each zone only.

Twenty-three of the total 50 diagnostic clay artefacts (including the 38 clay objects and also clay beads, figurines and pottery) come from middens (46\%). This reflects the distribution of clay objects and clay artefacts in general at Boncuklu Höyük (Fig. 13) (Bennison-Chapman 2014). Of the diagnostic artefacts, those recognised as adult female (78\% of diagnostic artefacts) are found in all context types, with no patterning evidenced in terms of the distribution of artefacts according to the age or sex of the prints found on them (Fig. 14). Only three specific context types are dominated by other clay artefacts (figurines and pottery, for example) and these prints are from adult females: "burnt structural material", "levelling material" and "mud brick collapse", yet the small number of these contexts might not be representative of the distribution of artefacts at the site in general. Fourteen diagnostic artefacts come from contexts within internal spaces/buildings, half of which are clay objects with the prints of adult females (Table 6). None are in situ, and most appear to be accidentally incorporated into structural material, infill or collapse material, thus mirroring the overall depositional patterning of clay objects. Only three of the 50 diagnostic clay artefacts are associated with floors, two as a structural element and one on the floor surface. All three display adult female prints and are clay objects.

\section{Discussion}

The crude appearance of small, geometric clay objects, along with their uncertain function has until recently led to a lack of interest and study when found at Neolithic sites in South-West Asia (BennisonChapman 2014). Indeed, doubt has existed as to whether or not these objects are artefacts at all, perhaps being naturally occurring clumps of clay, or pieces of clay flattened under foot or between two objects incidentally. Though fingertip-depressions can be felt on the surface of many clay objects, the clear and undisputable presence of palm print and fingerprint impressions as revealed by RTI is irrefutable evidence of the manipulation of clay in the human hand. The human-made impressions and the moulding of clay objects into a 3-Dimensional shape provide clear evidence that clay objects from Neolithic sites were intentionally crafted artefacts. They are not accidentally or incidentally occurring pieces of shaped clay, but rather objects of purpose. 
This research project proves the technique of RTI to be a highly useful tool in the confirmation and enhancement of human palm prints and fingerprints on small, geometric clay objects. The RTI images produced by the technique enable the accurate and reliable analysis of identified palm and fingerprints on Neolithic artefacts. The results of this project are striking; serving to bolster recently made claims that, in opposition to widely held assumptions, clay objects were intentionally crafted, utilitarian tools in the Neolithic of West Asia (Bennison-Chapman 2014). Secondly, the crude nature of the majority of clay objects has led to the assumption that even if they were indeed human-made, small children produced the objects, evidence of "doodles" rather than artefacts or tools serving any meaningful purpose within Neolithic communities (Broman Morales 1983: 386). Whilst their crude appearance is not denied, the results of this study demonstrate that adults, as opposed to children were the main producers of clay objects at Neolithic Boncuklu Höyük. Therefore it is unlikely these plentiful objects were unimportant items with no purpose. Lastly, the fact that not just adults, but adult females were the primary producers of clay objects at Boncuklu Höyük points to a gender based division of tasks at the site.

While some researchers consider the small clay objects to be children's playthings made by mothers to entertain their offspring, and evidence for children on site, more complex activities can be invoked for the women who were the primary makers of the clay objects at Boncuklu. Though the division of labour along gender lines is not unknown in the Neolithic Near East (i.e. Molleson 2000), undisputable evidence from such a small, and early Neolithic site is remarkable. Whether for gaming, divination or accountancy, this study of Boncuklu clay objects suggest women likely dominated the sphere of these ubiquitous objects. Though there is no direct evidence of the use of clay objects in divination or sortation (indeed it would be near impossible to prove in Neolithic archaeology); these practices are common throughout history. Lots can be a method of selecting people to fulfil a particular task (e.g. to fight or to go hunting), or to make other important decisions such as to distribute plots of land (Johnson 2011: 141; Latham 1859; Vinding 1998). If the clay objects were used in divination, certain women may have served as seers and/or leaders of ritualized activities, potentially playing a vital role in decision making within the community at Boncuklu Höyük (see Roeber 2008: 134, also Schlegel 1899). Similarly divination is a possible role for small geometric clay objects as part of ritual practice. In the context of the Neolithic period in West Asia, with its surge in ritual activities, the use of clay objects as a part of normal magic and ritual activity is not an unrealistic proposition. It can be imagined that like lots, clay objects (individually or as a group), were cast or drawn by an appointed person, with the selection of an object or group of objects with a particular quality (shape, colour, or displaying a particular marking or fold in the clay), or the resultant distribution of the objects interpreted as portraying a message from higher beings or signalling the outcome of a decision (e.g. Flad 2008; Laufer 1914: 191; Loewe 1988). 
Though evidence for the identity of the manufacturers is not conclusive evidence for the identity of the user, the clear division of labour along gender lines in their manufacture is strong enough evidence to suggested gender divisions existed in other lines of work and task-based activities. There is however, no evidence that their use-context was also gendered. The potential activities clay objects were used for could have utilised open-air midden areas if the entire community was involved in witnessing. Yet the performance of divination, the drawing or lots or decision making gaming are equally as likely to be undertaken in private, with a small, select audience of witnesses only. As the majority of clay objects (from the study sample as well as all examples recovered from Boncuklu Höyük more generally) are recovered from middens and secondary context types, the normal location of their use is uncertain. Nonmutually exclusive alternatives to divination and ritual suggest women used clay objects to count and keep track of the quantities of the supplies, including dietary resources and raw materials, even whilst men were engaged in tasks related to resource acquisition. These scenarios acknowledge women and men played equally important roles within the community at Boncuklu Höyük. Finally, we cannot discount the possibility that the women of Boncuklu were the primary gamers in the society, using the abundantly present hand-sized objects found on the site.

\section{Conclusion}

The study of palm prints and fingerprints on small clay objects from Boncuklu demonstrates the success of RTI in verifying, capturing and enhancing hand impressions on Neolithic clay artefacts, enabling a detailed analysis to be undertaken. The resultant prints were identified as adult/child, and the sex of the adult printers to be assessed. The results of this study definitively show that at Boncuklu Höyük, clay objects were indeed human-made artefacts, predominantly manufactured by adult females. Furthermore, this demographic identity did not change according to artefact shape, type, temporally, nor according to location of use or disposal. The technique is transferable to other clay artefact types. Though clay objects were the focus of this study, RTI and subsequent analysis had equal success on many other artefact types studied including figurines and clay beads. It was only on pottery where far fewer diagnostic prints proportionally were present. A larger study incorporating higher numbers of this broad range of artefact types has the potential to reveal details regarding the distribution and division of labour within a Neolithic community.

\section{ACKNOWLEDGEMENTS}

This work was supported by Pacific Legacy Inc., and carried out with the kind permission of Prof. Douglas Baird and Dr. Andrew Fairbairn, directors of the Boncuklu Höyük Project along with Dr Gökhan Mustafaoðlu, Assistant Site Director. 


\section{LIST OF CAPTIONS}

\section{FIGURES}

Figure 1: (top) Location of Boncuklu Höyük within Turkey's Konya Plain (Roberts \& Rosen 2009: fig. 1 p. 393). (Bottom) Plan of Boncuklu Höyük with the main excavation and "scrape" areas marked (Baird et. al. 2012: fig. 1 p. 239).

Figure 2: Range of typical small geometric clay objects or "tokens" from Boncuklu Höyük (left to right, top to bottom: SF\#'s 3518, 3127, 3488, 1526, 1483, 2924, 3094, 1508 \& 2169).

Figure 3: Example of a clay figurine from Boncuklu Höyük, SF1584-BK11. (Drawing: Caroline Hebron, courtesy of the Boncuklu Höyük Project).

Figure 4: Proportion of different clay artefacts studied (total $n=88$ ), by small find category.

Figure 5: 1) RTI Image Capture (a) stationary camera, standard prime lens (50mm or $100 \mathrm{~mm}$ ), handheld external flash, reflective spheres, multiple images taken at a specific angle and distance from object, (b) reflective spheres and scale in each frame; (c) blended sphere. 2) RTI Builder (v.2.0.2) (de) software builds 3-D images (polynomial texture maps) based on the pattern of light reflection from the surface under study, and based on the colour data in each image. 3) RTI Viewer (v.1.1) (f) Interactive post-processing software with the ability to move light across the surface (green ball), highlighting in 3-D the surface details. Different rendering modes are available. (Photographs: authors. diagrams: culturalheritageimaging.org).

Figure 6: Mean friction ridge density SF1102-adult female.

Figure 7: Top left: adult male SF2388 (BK2014, ceramic vessel fragment), bottom left adult male SF1563 (BK2012, clay object) and right: child SF1350 (BK2011, clay object).

Figure 8: Demographic profile of the $n=50$ diagnostic clay artefacts as analysed using RTI.

Figure 9: The demographic distribution of diagnostic finger/palm prints according to clay artefact type.

Figure 10: Diagnostic small, geometric clay objects only ( $\mathrm{n}=38)$; grouped by broad 3-Dimensional shape according to demography of the print maker.

Figure 11: Distribution, by excavation area, of the diagnostic clay artefacts $(n=50)$ with the diagnostic geometric clay objects highlighted.

Figure 12: Distribution of the 50 diagnostic clay artefacts, according to excavation area and demography.

Figure 13: Distribution of the 50 diagnostic clay artefacts according to context type and demography.

Figure 14: Contextual distribution of the 50 diagnostic clay artefacts according to demography.

\section{TABLES}

Table 1: Detail of the clay artefacts photographed and studied, according to on-site, typological classification. 
Table 2: The number and relative proportion of imaged vs. diagnostic (prints large and clear enough to reveal demographic data) artefacts by clay artefact type.

Table 3: The success of RTI in identifying and enhancing finger and palm prints to enable analysis and identification.

Table 4: Demography of the $n=50$ diagnostic clay artefacts, by artefact type.

Table 5: Demography of the $\mathrm{n}=38$ diagnostic clay objects: adult male (M), adult female (F) or child (Ch.) by degree of certainty.

Table 6: Distribution of diagnostic clay artefacts recovered from internal contexts ( $n=14$ out of 50) grouped by type of clay artefact according to the sex of the print maker, male (M) or female (F).

\section{REFERENCES}

Acree, M.A. 1999. Is There a Gender Difference in Fingerprint Ridge Density? Forensic Sci. Int. 102: $35-44$.

Ashbaugh D. 1999. Quantitative-Qualitative Friction Ridge Analysis: An introduction to basic and advanced ridgeology. CRC Press, Boca Raton, FL.

Baird, D. Forthcoming. Boncuklu Höyük vol. 1: Preliminary Report 2004-2010 Seasons. British Institute at Ankara (BIAA), London (tbc).

Baird, D., Fairbairn, A., Jenkins, E., Martin, L., Middleton, C., Pearson, J., Asouti, E., Edwards, Y., Kabukcu, C., Mustafaoğlu, G., Russell, N., Bar-Yosef, O., Jacobsen, G., Wu, X., Baker, A. \& Elliott, S. 2018. Agricultural Origins on the Anatolian Plateau, Proceedings of the National Academy of Sciences, 115/14, pp. E3077-86.

Baird, D. 2012. The Late Epipalaeolithic, Neolithic, and Chalcolithic of the Anatolian Plateau, 13,000 $-4,000$ BC. In: D. T. Potts (Ed.), A Companion to the Archaeology of the Ancient Near East, WileyBlackwell, Oxford, pp. 431-65.

Baird, D., Fairbairn, A., Martin, L. \& Middleton, C. 2012. The Boncuklu Project: The origins of sedentism, cultivation and herding in central Anatolia. In: M. Özdoğan, N. Başgelen \& P. Kuniholm (Eds.) The Neolithic in Turkey: New Excavations and New Research Vol. 3 Central Anatolia: 219-244. Arkeoloji ve Sanat Yayinlar: Istanbul. 
Baysal, E. 2013. A Tale of Two Assemblages: Early Neolithic manufacture and use of beads in the Konya Plain, Anatolian Studies 63: 1-15.

Bennison-Chapman, L. E. 2013. Geometric clay objects. In: I. Hodder (Ed.) Substantive Technologies at Çatalhöyük: Reports from the 2000-2008 seasons (Çatalhöyük Research Project 9): 253-276. British Institute at Ankara \& Cotsen Institute of Archaeology at UCLA: London \& Los Angeles.

Bennison-Chapman, L. E. 2014. The Role and Function of "Tokens" and Sealing Practices in the Neolithic of the Near East: The question of early recording systems, symbolic storage, precursors to writing, gaming, or monitoring devices in the world's first villages. Unpublished $\mathrm{PhD}$ thesis, University of Liverpool, UK.

Bolger, D. 2010. The Dynamics of Gender in Early Agricultural Societies of the Near East, Signs 35(2/2010): 503-31.

Bonora, G. L., Massimo, V., Mariottini, M. \& Guida, G. 2014. On the Use of Tokens and Seals along the Kopet Dagh Piedmont, Turkmenistan (ca 6000-3000 BCE), Paléorient 40(1): 55-71.

Broman Morales, V. 1983. Jarmo Figurines and Other Clay Objects. In: L. S. Braidwood, R. J. Braidwood, B. Howe, C. A. Reed \& P. J. Watson (Eds.), Prehistoric Archaeology along the Zagros Flanks, Oriental Institute of the University of Chicago, Chicago, pp. 369-423.

Broman Morales, V. 1990. Figurines and Other Clay Objects from Sarab and Çayönü. The Oriental Institute of the University of Chicago, Chicago.

Cultural Heritage Imaging (CHI) 2013a. Reflectance Transformation Imaging (RTI), Electronic document, http: //culturalheritageimaging.org/Technologies/RTI/, accessed August 2013.

Cultural Heritage Imaging (CHI) 2013b. How to Process: Do It Yourself. Electronic document, http: //culturalheritageimaging.org/What_We_Offer/Downloads/Process/index.html, accessed August 2013.

Cultural Heritage Imaging (CHI) 2013c. How to View: Do It Yourself. Electronic document, http: //culturalheritageimaging.org/What_We_Offer/Downloads/View/index.html, accessed August 2013.

Colledge, S., Conolly, J. \& Shennan, S. 2004. Archaeobotanical Evidence for the Spread of Farming in the Eastern Mediterranean, Curr. Anthrop, 45(S4): S35-S58. 
de Contenson, H. 1995. Figurines en Argile, In: H. de Contenson (Ed.), Aswad et Ghoraifé: Sites néolithiques en Damascène (Syrie) aux IXème et VIIIème millénaires avant l'ère chrétienne, Institut Francais d'Archeologie du Proche-Orient, Beyruit, pp. 179-91.

Flad, R. K. 2008. Divination and Power: A Multiregional View of the Development of Oracle Bone Divination in Early China, Curr. Anthrop, 49(3): 403-37.

Fletcher, A., Baird, D., Spataro, M. \& Fairbairn, A. 2017. Early Ceramics in Anatolia: Implications for the production and use of the earliest pottery. The evidence from Boncuklu Höyük. Cambridge Archaeological Journal, 27(2): 351-369.

Forouzan, F., Glover, J. B., Williams, F. \& Deocampo, D. 2012. Portable XRF Analysis of Zoomorphic Figurines, "Tokens," and Sling Bullets from Chogha Gavaneh, Iran, J. of Archaeol. Sci. 39(12): 353441.

Fuller, D.Q., Asouti, E. \& Purugganan, M.D. 2012. Cultivation as Slow Evolutionary Entanglement: Comparative data on rate and sequence of domestication. Vegetation History and Archaeobotany, 21(2): 131-145.

Fuller, D.Q., Willcox, G. \& Allaby, R.G. 2011. Cultivation and Domestication Had Multiple Origins: Arguments against the core area hypothesis for the origins of agriculture in the Near East. World Archaeol. 43(4): 628-652.

Garfinkel, Y. \& Dag, D. 2006. Gesher: A Pre-Pottery Neolithic A Site in the Central Jordan Valley, Israel. A Final Report, Ex Oriente, Berlin.

Gutiérrez - Redomero, E., Alonso, C., Romero, E. \& Galera, V. 2008. Variability of Fingerprint Ridge Density in a Sample of Spanish Caucasians and its Application to Sex Determination, Forensic Sci. Int.180(1): 17-22.

Hager, L.D., Unpublished Report. An evaluation of baked clay objects from Yeşilova Höyük, Western Anatolia, Turkey using Reflectance Transformation Imaging (RTI) to detect palm prints, fingerprints, and other evidence of Neolithic hand use. Report submitted to the Yeşilova Höyük Research Project, Dr. Z. Derin, Ege University, Turkey, 2018.

Ibáñez, J. J. ed. 2008. Le site néolithique de Tell Mureybet (Syrie Du Nord)-Volume I \& II, BAR International Series 1843, Oxford. 
Johnson, W. 2011. Byways in British Archaeology. Cambridge University Press, Cambridge.

Kamp, K.A., Timmerman, N., Lind, G., Graybill, J. \& Natowsky, I. 1999. Discovering Childhood: Using fingerprints to find children in the archaeological record. Am. Antiq. 64/2 (April): 309-15.

Kenyon, K.M. \& Holland, T.A. 1983. Excavations at Jericho Volume 5: The Pottery Phases of the Tell and Other Finds, British School of Archaeology in Jerusalem c/o The British Academy, London.

Králík, M. \& Novotný, V. 2005. Dermatoglyphics of Ancient Ceramics. In: J. Svoboda (Ed.) Pavlov I Southeast: A Window in Gravettian Lifestyles, Academy of Sciences of the Czech Republic, Institute of Archaeology at Brno, pp. 449-477.

Latham, R. G. 1859. Descriptive Ethnology. J. van Voorst, London.

Laufer, B. 1914. Bird Divination among the Tibetans (Notes on Document Pelliot No. 3530, with a Study of Tibetan Phonology of the Ninth Century), T'oung Pao Second Series, vol. 15(1): 1-110.

Leo Oppenheim, A. 1959. On an Operational Device in Mesopotamian Bureaucracy, Journal of Near Eastern Studies, vol. 18(2): 121-28.

Loewe, M. 1988. Divination by Shells, Bones and Stalks during the Han Period, T'oung Pao Second Series, vol. 74/1(3): 81-118.

Mahasneh, H.M. \& Gebel, H.G. 1998. Geometric Objects from LPPNB Es-Sifiya, Wadi Mujib, Jordan, Paléorient, vol. 24(2): 105-10.

Malzbender, T, Gelb, D. \& Wolters, H. 2001. HP LABS Polynomial Texture Mapping (PTM). Electronic document, http: //www.hpl.hp.com/research/ptm/, accessed August 2013.

Matthews, R., Matthews, W. \& Mohammadifar, Y. (Eds.) 2013. The Earliest Neolithic of Iran: 2008 Excavations at Sheikh-e Abad and Jani, Oxbow Books, Oxford.

Molleson, T. I. 2000. The people of Abu Hureyra. In: A. M. T. Moore, G. C. Hillman \& A. J. Legge (Eds.), Village on the Euphrates: From Foraging to Farming at Abu Hureyra, Oxford University Press, Oxford, pp. 301-24. 
Morsch, M.G.F. 2002. Magic Figurines? Some Remarks About the Clay Objects of Nevalı Cori. In: H.G.K. Gebel, B.D. Hermansen \& C. Hoffmann Jensen (Eds.), Magic Practices and Ritual in the Near Eastern Neolithic, Ex Oriente, Berlin, pp. 145-162.

Mudge, M., Schroer, C., Noble, T., Matthews, N. Rusinkiewicz, S. \& Toler--Franklin, C. 2012. Robust, Scientifically Reliable Rock Art Documentation from Digital Photographs, In: J. McDonald \& P. Veth (Eds.), A Companion to Rock Art, Wiley--Blackwell.

Mudge, M. Schroer, C., Earl, G. Martinez, K., Pagi, H. Toler--Franklin, C., Rusinkiewicz, S., Ashley, M., Matthews, N., Noble, T., \& Dellepiane, M. 2010. Principles and Practices of Robust, Photography--based Digital Imaging Techniques for Museums, VAST 2010: The 11th International Symposium on Virtual Reality, Archaeology and Cultural Heritage, September 21-24, 2010, The Louvre, Paris, France.

Mudge, M., Malzbender, T., Schroer, C. \& Lum, M. 2006. New Reflection Transformation Imaging Methods for Rock Art and Multiple-Viewpoint Display, VAST 2006: The 7th International Symposium on Virtual Reality, Archaeology and Cultural Heritage, November 2006, Nicosia, Cyprus.

Nashli, H. F. \& Moghimi, N. 2013. Counting Objects: New Evidence from Tepe Zagheh, Qazvin Plain, Iran, Antiquity Project Gallery 87.

Nayak, V.C., Rastogi, P., Kanchan, T., Yoganarasimha, K., Kumar, G.P. \& Menezes, R.G. 2010. Sex Differences from Fingerprint Ridge Density in Chinese and Malaysian Population, Forensic Sci. Int. 197/1: 67-69.

Nissen, H.J., Damerow, P. \& Englund, R.K. 1993. Archaic Bookkeeping: Early Writing and Techniques of Economic Administration in the Ancient Near East. Chicago: University of Chicago Press.

Redman, J. \& Mudge, M. 2007. The Simultaneous Capture of Spectral and Textural Information, Society for Imaging Science and Technology 2007, May 21--24, 2007, Arlington, Virginia.

Roberts, N. \& Rosen, A. 2009. Diversity and Complexity in Early Farming Communities of Southwest Asia: New insights into the economic and environmental basis of Neolithic Çatalhöyük. Current. Anthropology 50(3): 393-402.

Robinson, A. 2007. The Story of Writing: Alphabets, Hieroglyphs and Pictograms, Thames \& Hudson, London. 
Sampson, G. 1985. Writing Systems: A linguistic introduction. Stanford: Stanford University Press.

Sanders, A. 2015. Fingerprints: Sex, state, and the organization of the Tell Leilan ceramic industry, J. of Archaeol. Sci. 57(2015): 223-238.

Schmandt-Besserat, D. 1996. How Writing Came About, University of Texas Press, Austin.

Schmandt-Besserat, D. 1992. Before Writing, Volume I: From Counting to Cuneiform, University of Texas press, Austin.

Schoerer, C., 2012. Advanced Imaging Tools for Museum and Library Conservation and Research, Bulletin of the American Society for Science and Technology, February/March.

Schneider, T. D. \& L. D. Hager, 2017. Detailing the Bead-Maker: Reflectance Transformation Imaging (RTI) of Steatite Disk Beads from Prehistoric Napa Valley, California. In: D. Bar-Yosef, Bonsall, C. \& Choyke, A. M. (Eds.), Not Just for Show: The Archaeology of Beads, Beadwork and Personal Ornaments, OxBow Books, Oxford \& Philadelphia, 36-158.

Taduran, R.J., Tadeo, A.K.V., C. Escalona, N.A.C., \& Townsend, G.C. 2016. Sex Determination From Fingerprint Ridge Density and White Line Counts in Filipinos, J. of Compar. Hum. Biol., vol. 67(2): 163-171.

Vinding, M. 1998. The Thakali: A Himalayan Ethnology. Chicago University Press, Chicago. 


\section{FIGURES}

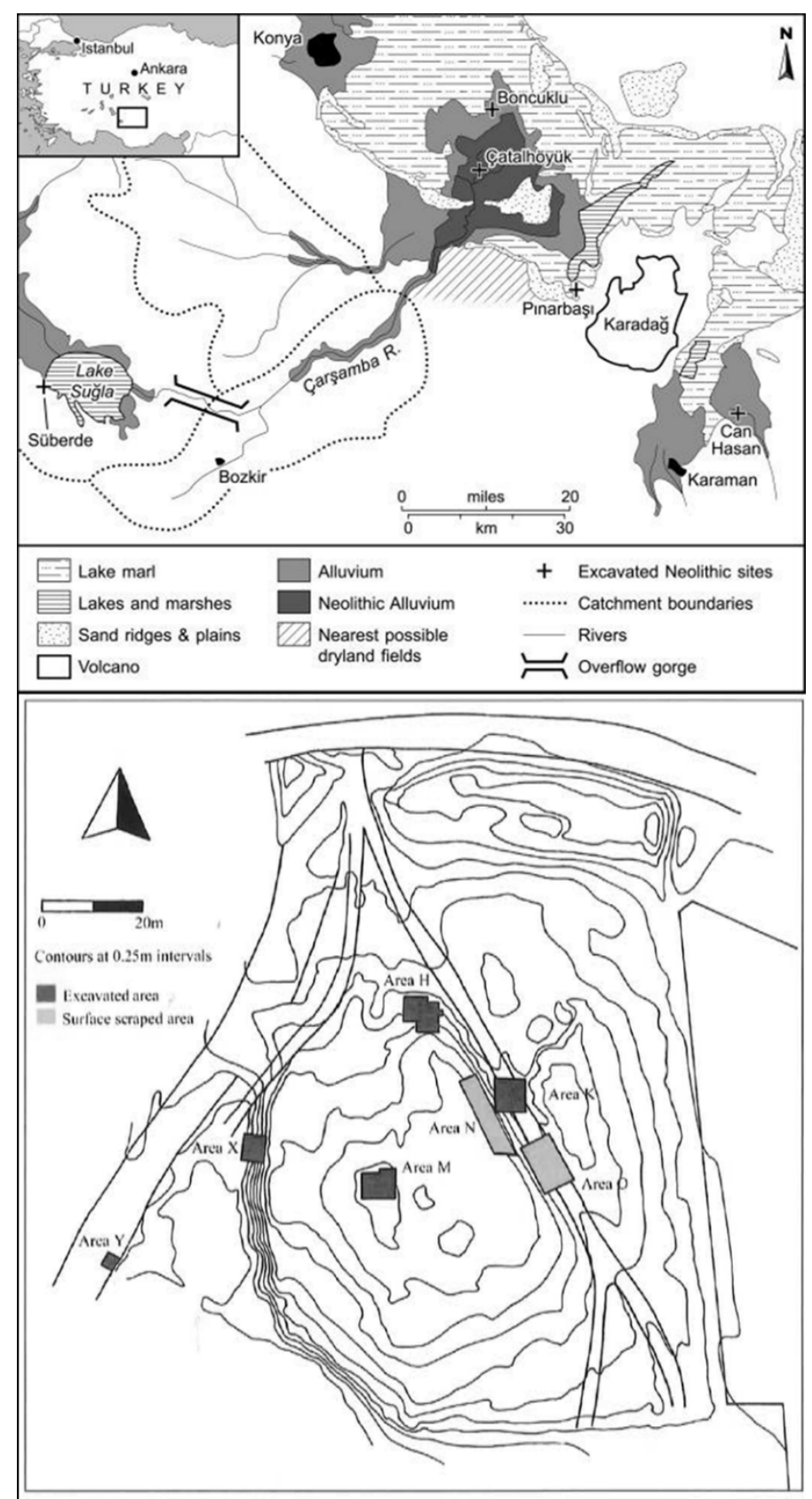

Figure 1: (top) Location of Boncuklu Höyük within Turkey's Konya Plain (Roberts \& Rosen 2009: fig. 1 p. 393). (Bottom) Plan of Boncuklu Höyük with the main excavation and "scrape" areas marked (Baird et. al. 2012: fig. 1 p. 239).

[1-column fitting image] 


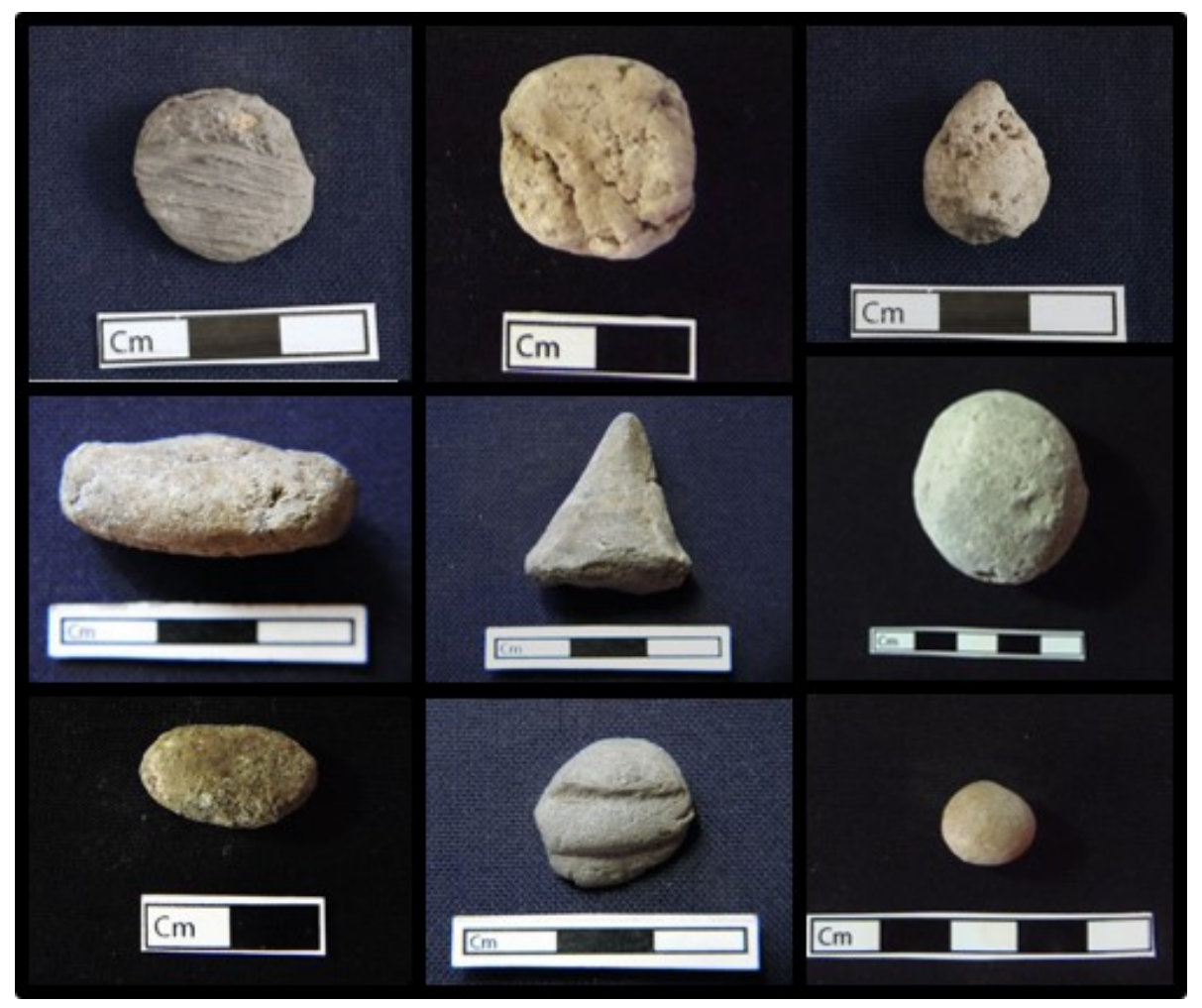

Figure 2: Range of typical small geometric clay objects or "tokens" from Boncuklu Höyük (left to right, top to bottom: SF\#'s 3518, 3127, 3488, 1526, 1483, 2924, 3094, 1508 \& 2169).

[1.5-column fitting image]

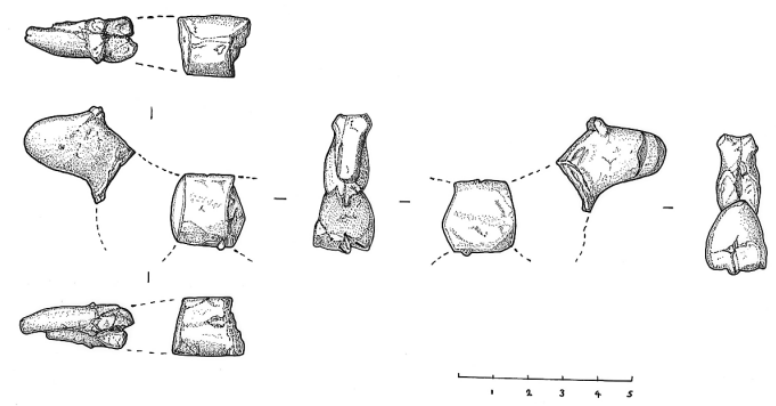

Figure 3: Example of a clay figurine from Boncuklu Höyük, SF1584-BK11. (Drawing: Caroline Hebron, courtesy of the Boncuklu Höyük Project).

[1.5-column-fitting image] 


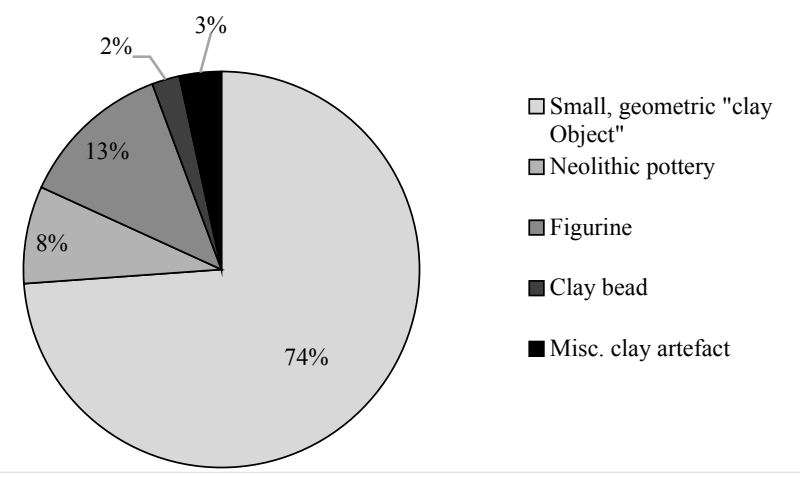

Figure 4: Proportion of different clay artefacts studied (total $n=88$ ), by small find category.

[1-column-fitting image]

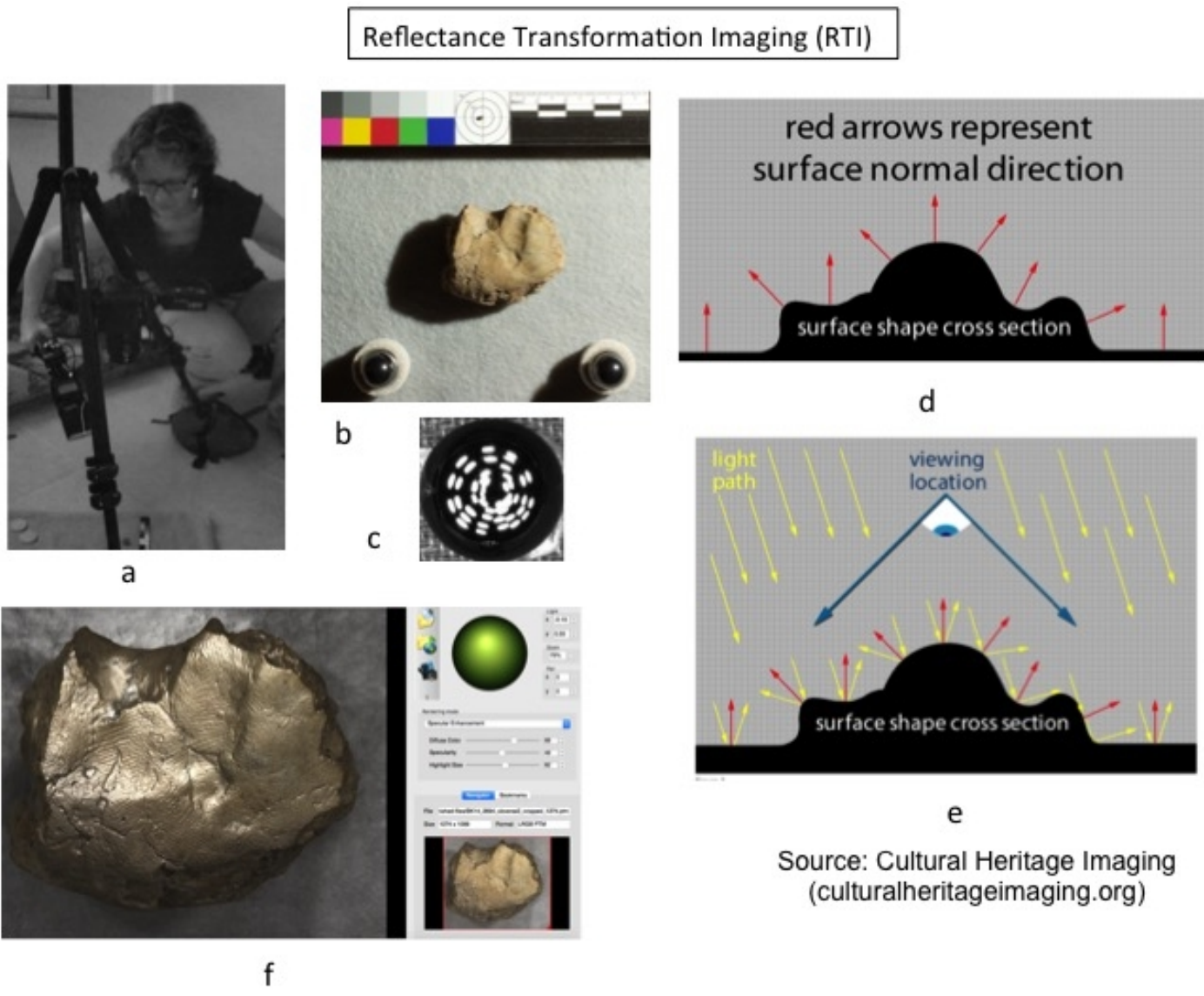

Figure 5: 1) RTI Image Capture (a) stationary camera, standard prime lens (50mm or $100 \mathrm{~mm}$ ), handheld external flash, reflective spheres, multiple images taken at a specific angle and distance from object, (b) reflective spheres and scale in each frame; (c) blended sphere. 2) RTI Builder (v.2.0.2) (de) software builds 3-D images (polynomial texture maps) based on the pattern of light reflection from the surface under study, and based on the colour data in each image. 3) RTI Viewer (v.1.1) (f) Interactive post-processing software with the ability to move light across the surface (green ball), highlighting in 3-D the surface details. Different rendering modes are available. (Photographs: authors. diagrams: culturalheritageimaging.org).

\section{[2-column fitting image]}




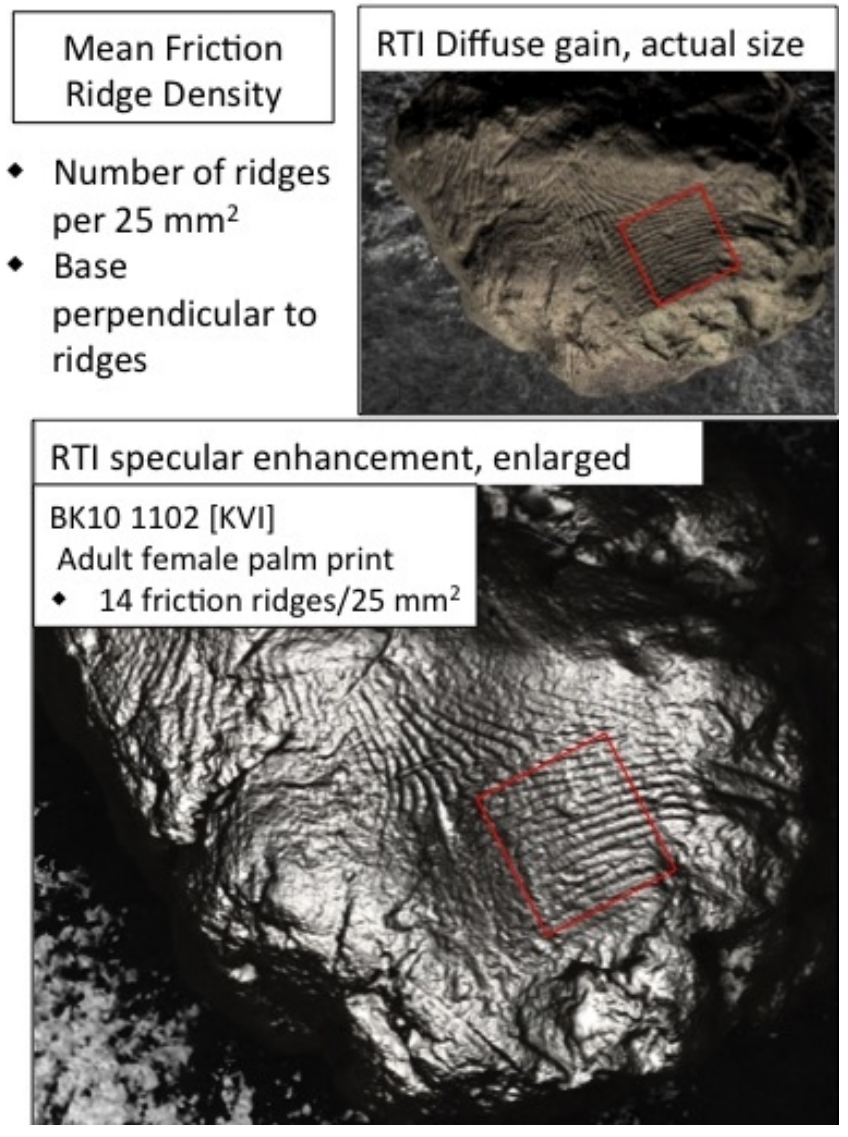

Figure 6: Mean friction ridge density SF1102-adult female.

\section{[1.5-column fitting image]}




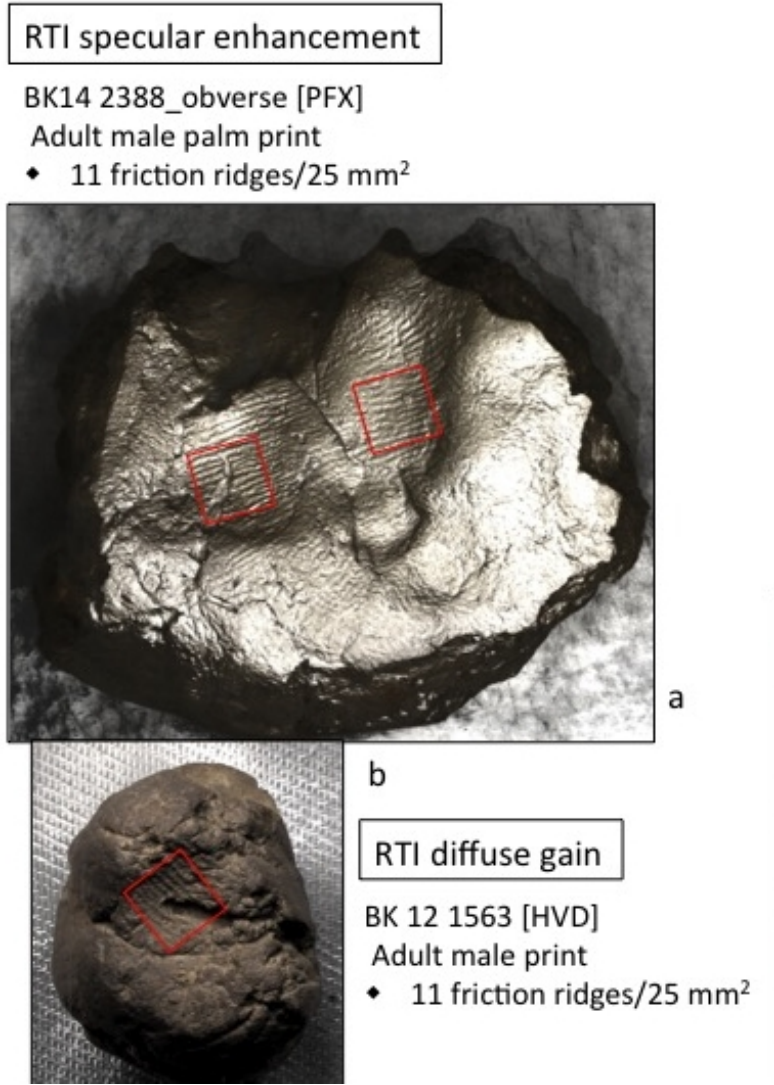

RTI specular enhancement

BK 111350 [QAE]

Child hand print

- $15+$ friction ridges $/ 25 \mathrm{~mm}^{2}$

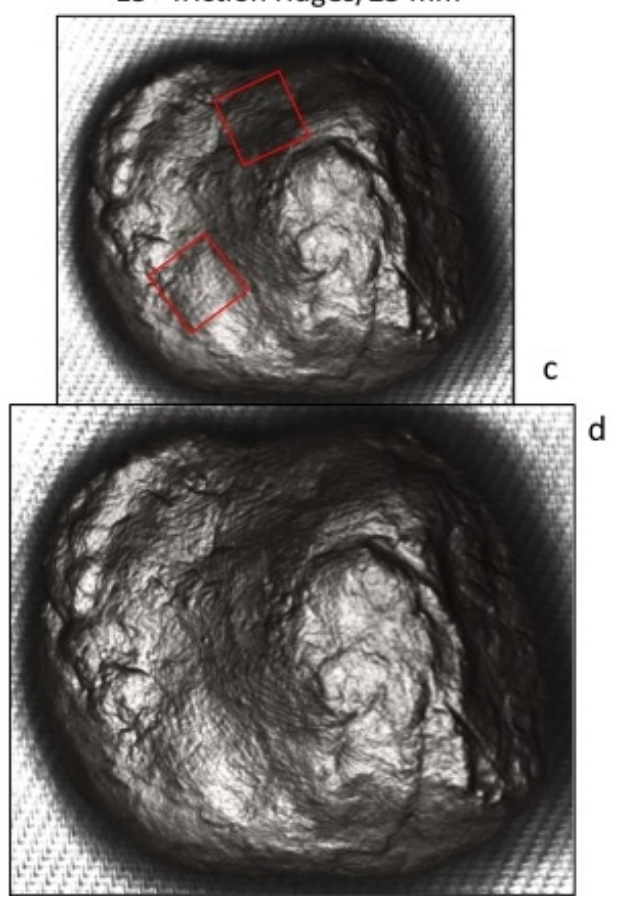

Figure 7: Top left: adult male SF2388 (BK2014, ceramic vessel fragment), bottom left adult male SF1563 (BK2012, clay object) and right: child SF1350 (BK2011, clay object).

[2-column fitting image] 


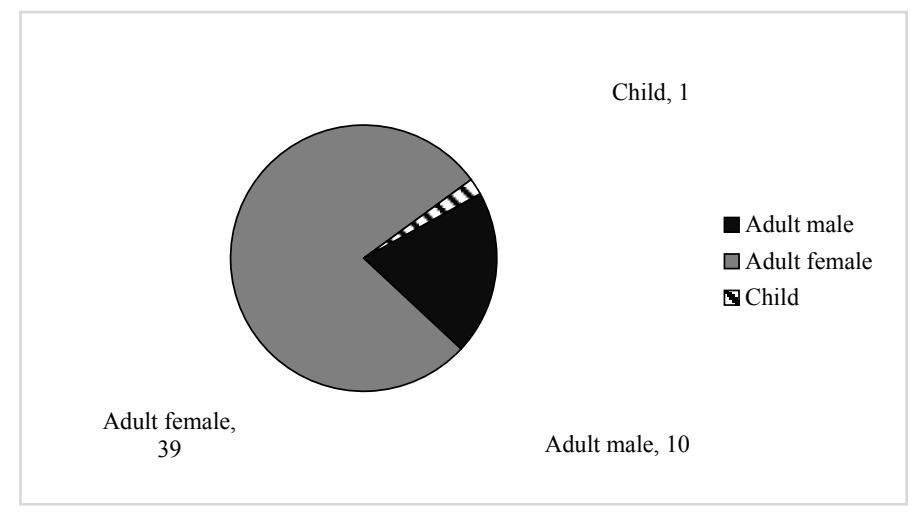

Figure 8: Demographic profile of the $n=50$ diagnostic clay artefacts as analysed using RTI. [1-column-fitting image]

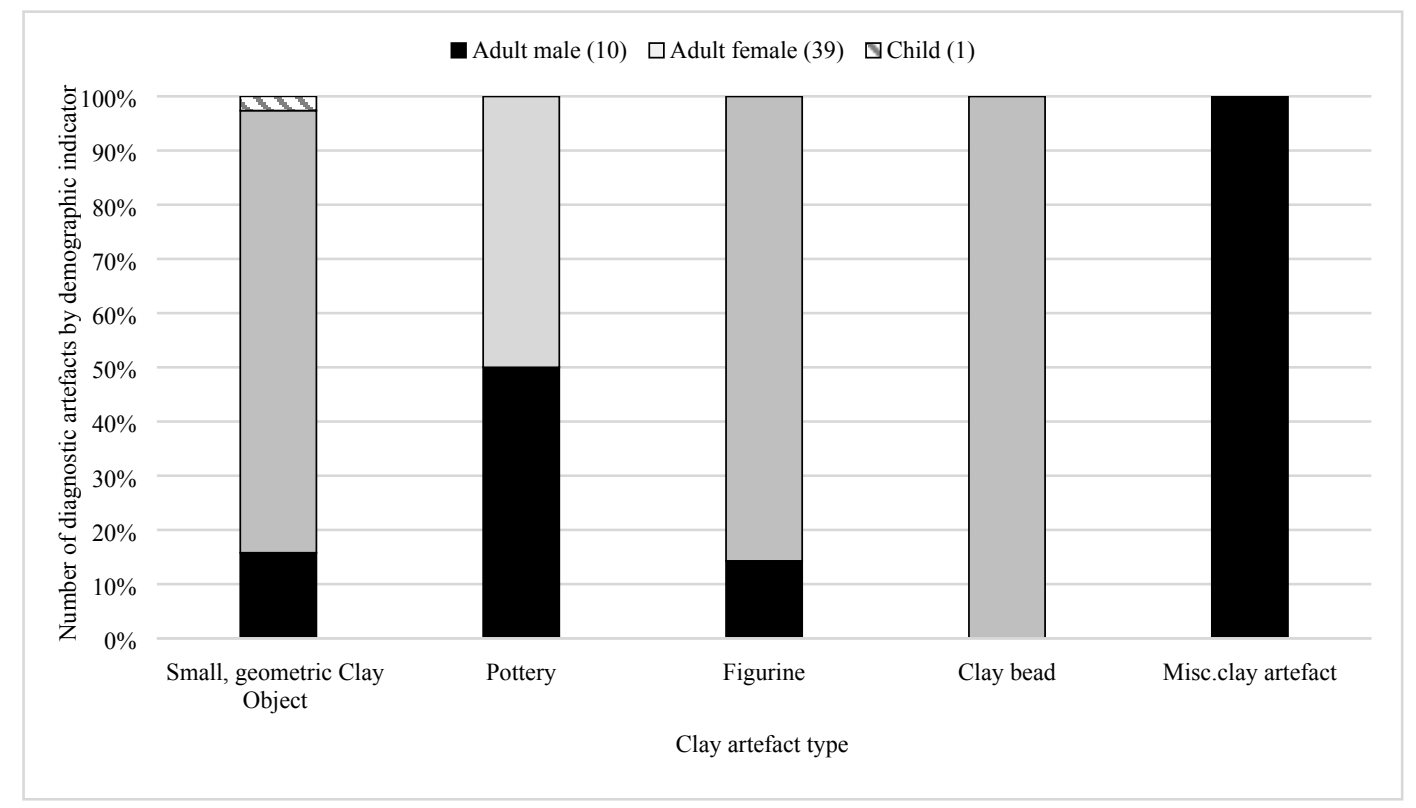

Figure 9: The demographic distribution of diagnostic finger/palm prints according to clay artefact type.

[1.5-column-fitting image] 


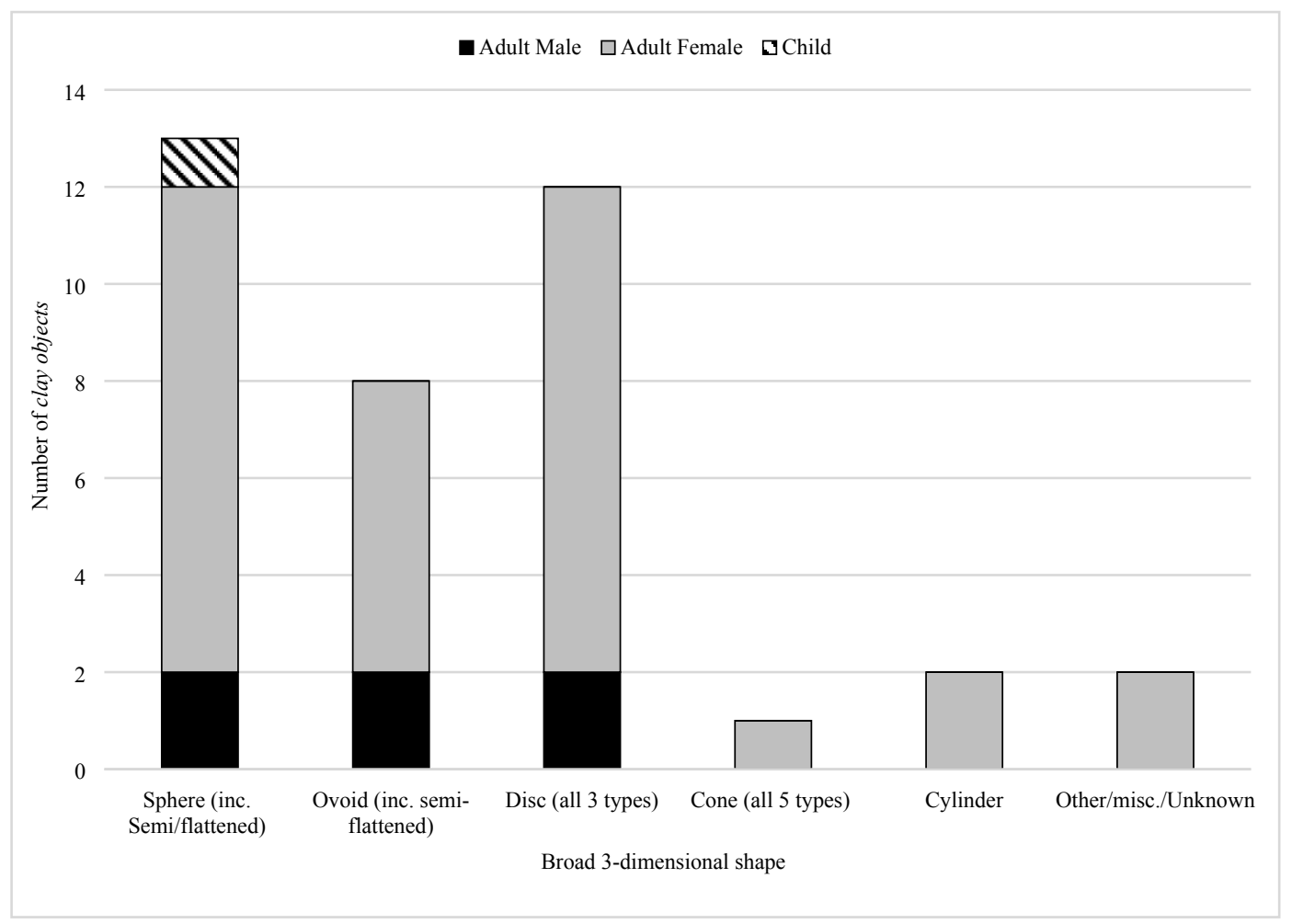

Figure 10: Diagnostic small, geometric clay objects only $(\mathrm{n}=38)$; grouped by broad 3-Dimensional shape according to demography of the print maker.

[1.5-column-fitting image]

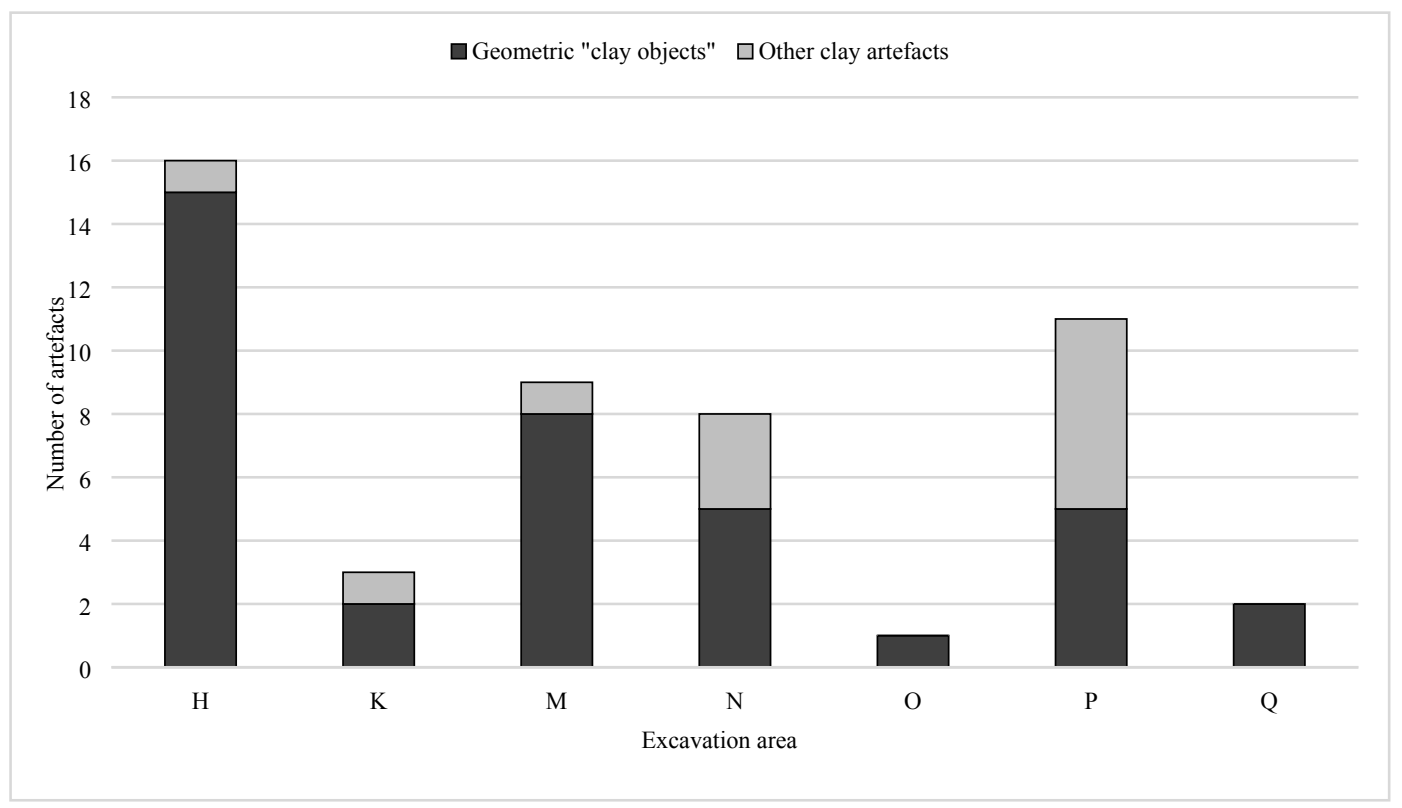

Figure 11: Distribution, by excavation area, of the diagnostic clay artefacts $(n=50)$ with the diagnostic geometric clay objects highlighted.

\section{[1.5-column-fitting image]}




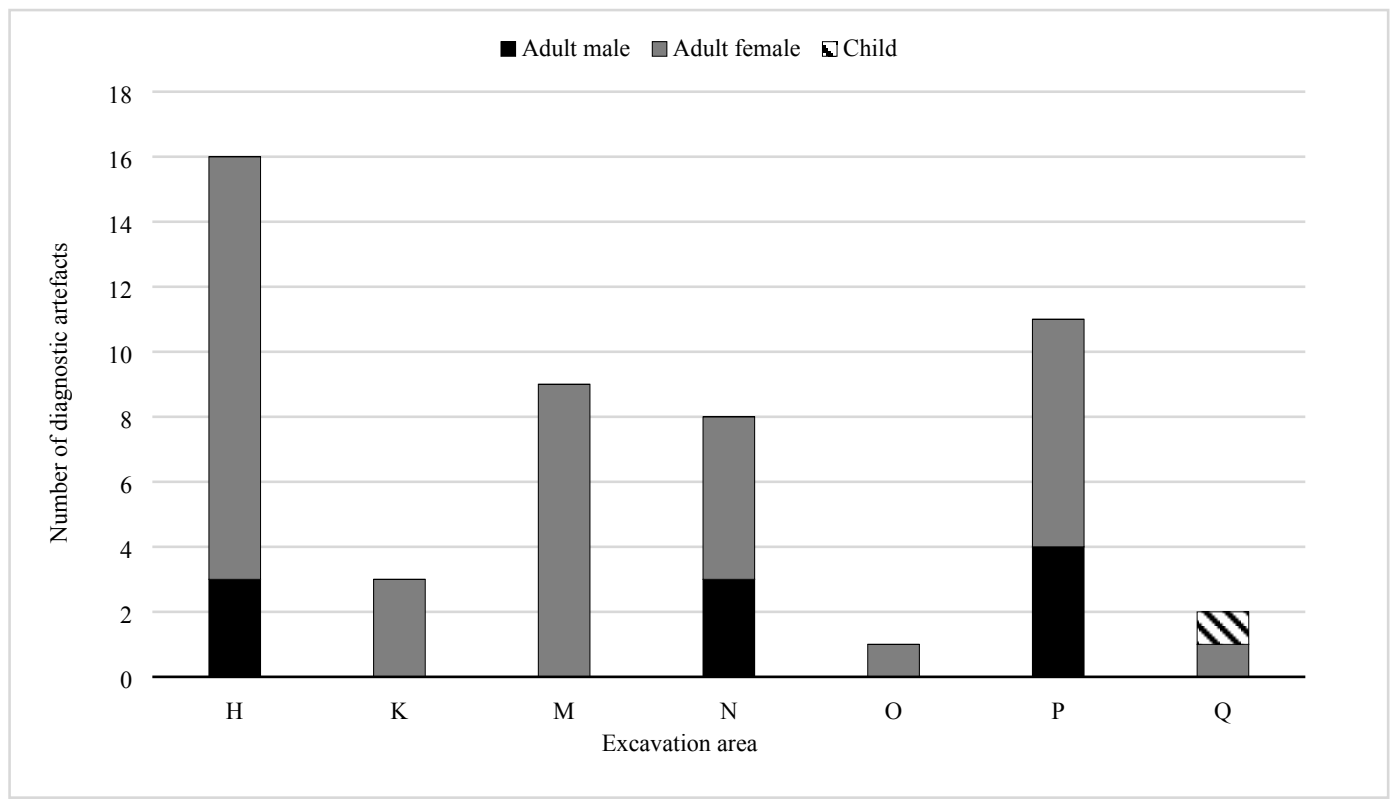

Figure 12: Distribution of the 50 diagnostic clay artefacts, according to excavation area and demography.

[1.5-column-fitting image]

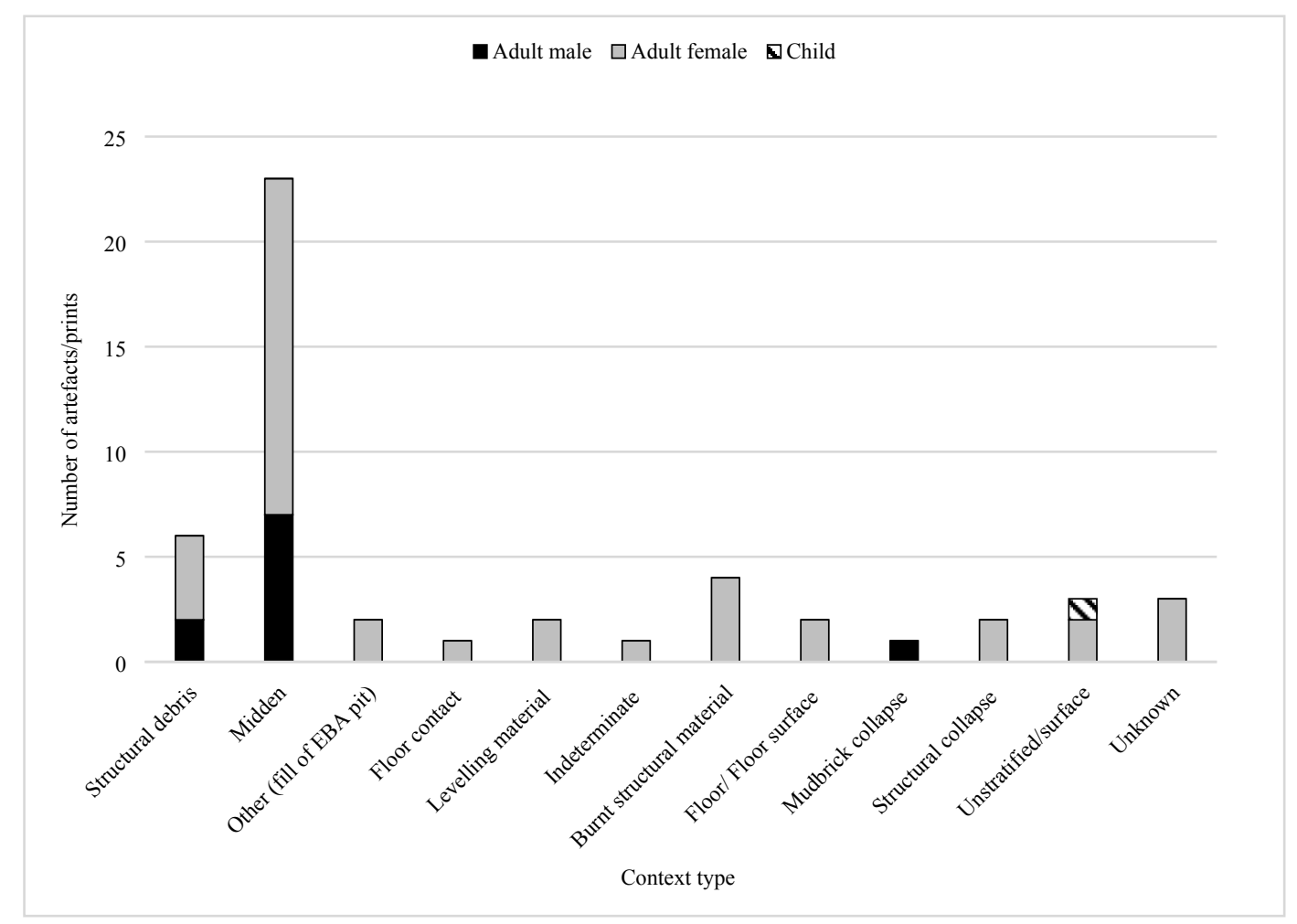

Figure 13: Distribution of the 50 diagnostic clay artefacts according to context type and demography. [2-column-fitting image] 


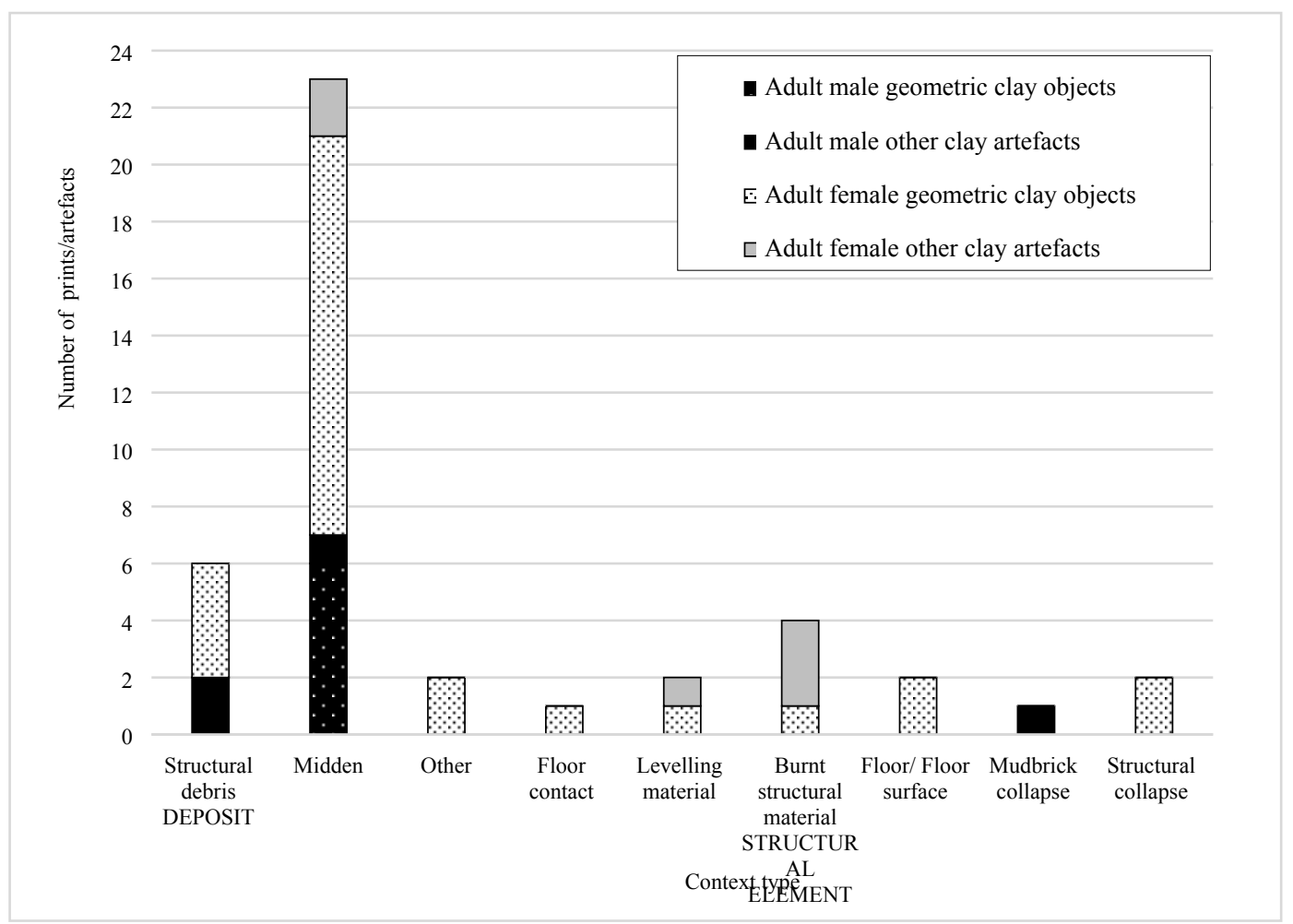

Figure 14: Contextual distribution of the 50 diagnostic clay artefacts according to demography. [1.5-column-fitting image] 


\section{TABLES}

\begin{tabular}{lc}
\hline Artefact type & $\begin{array}{c}\text { Object } \\
\text { count }\end{array}$ \\
\hline Clay object & $\mathbf{6 5}$ \\
All other clay artefact types (see below) & $\mathbf{2 3}$ \\
Pottery & 7 \\
Clay figurine & 11 \\
Clay bead & 2 \\
Misc. clay artefact & 3 \\
Total & $\mathbf{8 8}$ \\
\hline
\end{tabular}

Table 1: Detail of the clay artefacts photographed and studied, according to on-site, typological classification. [1-column-fitting image]

\begin{tabular}{lccc}
\hline Artefact type & $\begin{array}{l}\text { Imaged } \\
\text { count }\end{array}$ & $\begin{array}{l}\text { Diagnostic } \\
\text { count }\end{array}$ & $\begin{array}{l}\text { Percentage } \\
\text { of category } \\
\text { diagnostic }\end{array}$ \\
\hline Clay Object & 65 & 38 & $58.46 \%$ \\
Pottery & 7 & 2 & $28.57 \%$ \\
Clay figurine & 11 & 7 & $63.64 \%$ \\
Clay bead & 2 & 1 & $50.00 \%$ \\
Misc. clay artefact & 3 & 2 & $66.67 \%$ \\
Total & $\mathbf{8 8}$ & $\mathbf{5 0}$ & $\mathbf{5 6 . 8 2 \%}$ \\
\hline
\end{tabular}

Table 2: The number and relative proportion of imaged vs. diagnostic (prints large and clear enough to reveal demographic data) artefacts by clay artefact type.

[1-column-fitting image] 


\begin{tabular}{lcc}
\hline RTI success & Count & $\begin{array}{l}\text { \% of } \\
\text { imaged } \\
\text { artefacts }\end{array}$ \\
\hline Diagnostic prints & $\mathbf{5 0}$ & $\mathbf{5 6 . 8 2}$ \\
All undiagnostic & $\mathbf{3 8}$ & $\mathbf{4 3 . 1 8}$ \\
Undiagnostic detail: & & \\
Prints too faint/too few & $\mathbf{7}$ & 7.95 \\
Fingernail marks and \\
depressions only \\
Notal
\end{tabular}

Table 3: The success of RTI in identifying and enhancing finger and palm prints to enable analysis and identification.

[1-column-fitting image]

\begin{tabular}{lcccccc}
\hline Age/sex & $\begin{array}{l}\text { Clay } \\
\text { Object }\end{array}$ & Pottery & $\begin{array}{l}\text { Clay } \\
\text { figurine }\end{array}$ & $\begin{array}{c}\text { Clay } \\
\text { bead }\end{array}$ & Misc. & Total \\
\hline Adult male (10) & 6 & 1 & 1 & 0 & 2 & $\begin{array}{c}\mathbf{1 0} \\
(20 \%) \\
\mathbf{3 9}\end{array}$ \\
Adult female (39) & 31 & 1 & 6 & 1 & 0 & $\begin{array}{c}(78 \%) \\
\mathbf{1}\end{array}$ \\
Child (1) & 1 & 0 & 0 & 0 & 0 & $(2 \%)$ \\
Total diagnostic & $\mathbf{3 8}$ & $\mathbf{2}$ & $\mathbf{7}$ & $\mathbf{1}$ & $\mathbf{2}$ & $\mathbf{5 0}$ \\
\hline
\end{tabular}

Table 4: Demography of the $n=50$ diagnostic clay artefacts, by artefact type.

[1.5-column-fitting image]

\begin{tabular}{lccc}
\hline $\begin{array}{l}\text { Small, geometric Clay } \\
\text { Objects only }(\mathbf{n}=\mathbf{3 8})\end{array}$ & Demographic markers & \\
\hline Degree of certainty & M & F & Ch. \\
Definite & 5 & 30 & 1 \\
Possible & 1 & 1 & 0 \\
All & 6 & 31 & 1 \\
\hline
\end{tabular}

Table 5: Demography of the $n=38$ diagnostic Clay Objects adult male (M), adult female (F) or child (Ch.) by degree of certainty.

[1-column-fitting image] 


\begin{tabular}{|c|c|c|c|c|c|c|c|c|c|c|c|c|c|c|}
\hline \multirow{2}{*}{ 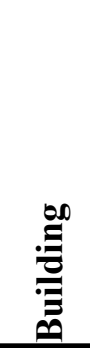 } & \multirow{2}{*}{ 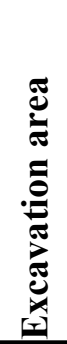 } & \multirow{2}{*}{ 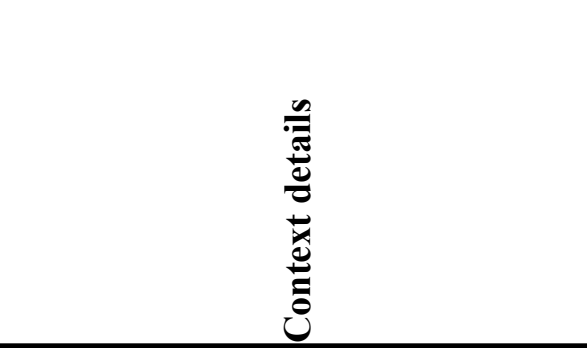 } & \multirow{2}{*}{ 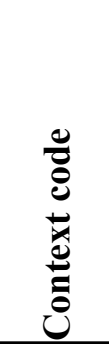 } & \multirow{2}{*}{ 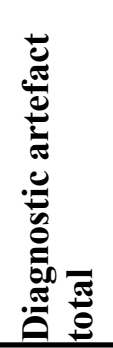 } & \multicolumn{2}{|c|}{ 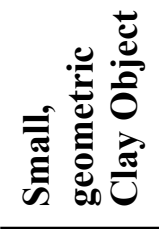 } & \multicolumn{2}{|c|}{ 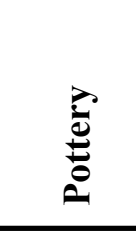 } & \multicolumn{2}{|c|}{ 氞 } & \multicolumn{2}{|c|}{ 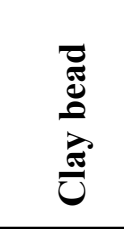 } & \multicolumn{2}{|c|}{ 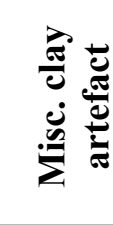 } \\
\hline & & & & & $\mathbf{M}$ & $\mathbf{F}$ & $\mathbf{M}$ & $\mathbf{F}$ & $\mathbf{M}$ & $\mathbf{F}$ & $\mathbf{M}$ & $\mathbf{F}$ & $\mathbf{M}$ & $\mathbf{F}$ \\
\hline B.4 & $\mathrm{H}$ & $\begin{array}{l}\text { Structural fill: "Upper compact rubble } \\
\text { fill of building } 4 " \text { ". }\end{array}$ & HLD & 1 & & 1 & & & & & & & & \\
\hline B.9 & K & Dirty floor surface, space 1, Building 9. & KVI & 1 & & 1 & & & & & & & & \\
\hline B.2 & $\mathrm{K}$ & "Levelling material, fill of Building 2". & KWR & 1 & & & & & & 1 & & & & \\
\hline B.2 & K & As above & KYV & 1 & & 1 & & & & & & & & \\
\hline B.16 & $\mathrm{M}$ & $\begin{array}{l}\text { "Structural collapse, From the roof of } \\
\text { Building 16". }\end{array}$ & MZY & 1 & & 1 & & & & & & & & \\
\hline B.6 & $\mathrm{N}$ & "Rubble fill of Building 6". & NBQ & 4 & & 2 & & & 1 & & & & 1 & \\
\hline B.21 & $\mathrm{P}$ & $\begin{array}{l}\text { "Mudbrick collapse within Building } \\
21 " .\end{array}$ & PFX & 1 & & & & & & & & & 1 & \\
\hline B.20 & $\mathrm{P}$ & $\begin{array}{l}\text { "Burnt structural material on the floor } \\
\text { of Building } 20 \text { ". }\end{array}$ & PGU & 1 & & 1 & & & & & & & & \\
\hline B.20 & $\mathrm{P}$ & As above & $\mathrm{PHC}$ & 3 & & & & 1 & & 2 & & & & \\
\hline \multicolumn{3}{|c|}{ TOTAL: } & & 14 & & 7 & & 1 & 1 & 3 & & & 2 & \\
\hline
\end{tabular}

Table 6: Distribution of diagnostic clay artefacts recovered from internal contexts ( $\mathrm{n}=14$ out of 50$)$ grouped by type of clay artefact according to the sex of the print maker, male (M) or female (F).

[2-column-fitting image] 